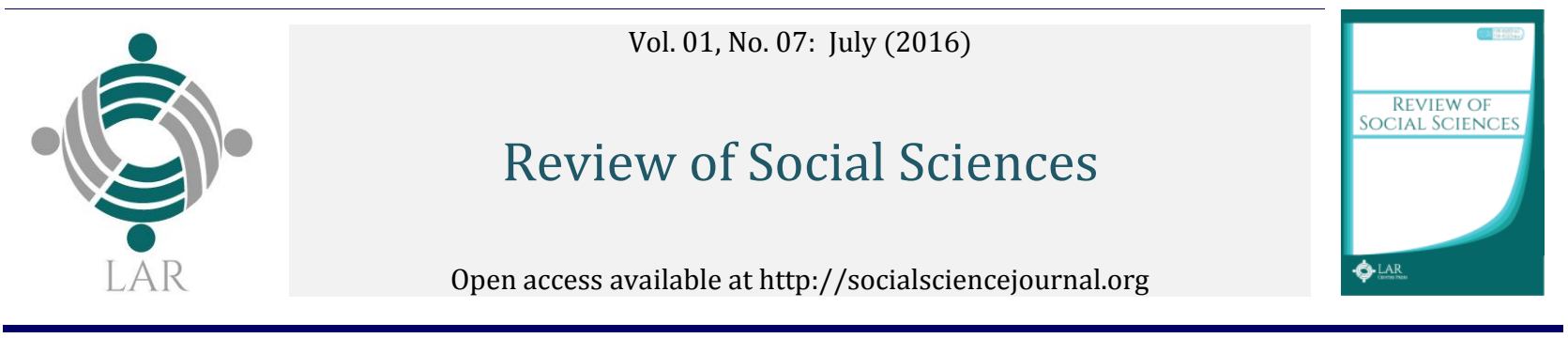

\title{
The Naturalization of U.S. Immigrants: Why Citizenship Rates Differ by State
}

\author{
Tamara M. Woroby, Ph.D. a*, Melissa A. Osborne Groves, Ph.D. ${ }^{\mathrm{b}}$ \\ a Professor of Economics, Towson University, Department of Economics, Towson, MD. 21252, and \\ Senior Adjunct Professor, Johns Hopkins University, School of Advanced International Studies, Washington, DC, 20036. \\ b Towson University, Associate Professor of Economics, Department of Economics, Towson, MD. 21252. \\ Email: mgroves@towson.edu \\ ${ }^{*}$ Corresponding author's email address: tworoby@towson.edu
}

\section{AR T I C LE IN F O}

Received: 15-06-2016

Accepted: 01-07-2016

Available online: 12-07-2016

\section{Keywords:}

Citizenship rates;

Mexican immigrants;

Naturalization;

U.S. immigration;

Undocumented immigration.

JEL Classification:

J61

\section{A B S T R A C T}

This paper investigates the extent to which the geographic region in which an immigrant resides influences the propensity to naturalize, by specifically analyzing the variation in U.S. immigrant citizenship rates across states. By merging Census data with other forms of publically available state level data, we are able to better understand why state naturalization rates in the U.S. vary so dramatically, from a low of about $30 \%$ to a high of almost $60 \%$. We utilize composite variables in a simple OLS framework to maximize sample size and test to ensure our estimates are unbiased and valid for statistical inference. We find that while applying for citizenship is an individual decision, both institutional and group variables influence this decision. Consistent with prior research, our results indicate that a more favorable economic environment is correlated with higher naturalization rates and that the clustering of Mexicans discourages naturalization. Our results also indicate that states that are more socially and politically welcoming to immigrants have statistically higher rates of naturalization, and that there are no significant negative effects on naturalization rates in states with larger numbers of undocumented immigrants. Our research contributes to the growing body of literature on naturalization decisions and supports the proposition that attitudes towards immigrants, be they authorized or undocumented, influence the extent to which the foreign born will choose to become fuller participants in U.S. society.

This is an open access article under the terms of the Creative Commons Attribution License 4.0, which allows use, distribution and reproduction in any medium, provided the original work is properly cited.

DOI: http://dx.doi.org/10.18533/rss.v1i7.45 ISSN: 2378-8569 (Print), 2378- 8550 (Online)

\subsection{Introduction}

A "pathway to citizenship" is an often used phrase in the current debate on U.S. immigration, and focuses on how to deal with the large number of undocumented in the population. This phrase implicitly assumes that the end point of legal immigration is the attainment of citizenship. However, if the undocumented (if ever eligible) naturalize at the same rate that legal permanent residents in the United States currently do - the reality is that many will never choose to become citizens.

In an attempt to add to the growing body of research on the determinants of naturalization, this paper investigates the extent to which the geographic region in which an immigrant resides influences the propensity to naturalize, by specifically analyzing the variation in U.S. immigrant citizenship across states. Section 2 of the 
paper sets the naturalization decision within a cost-benefit framework, observes that citizenship rates vary depending upon the state in which U.S. immigrants reside, and underlines that, both in a global comparative context as well as in a historical context, naturalization rates in the United States are surprisingly low. Some of the main determinants of naturalization, as have been considered in the theoretical literature, are then reviewed. In Section 3, we develop an empirical model to explain the observed variation in naturalization rates across U.S. states. We utilize composite variables in a simple OLS framework to maximize sample size and test to ensure our estimates are unbiased and valid for statistical inference. Our statistical results are discussed in Section 4, and the main conclusions and policy implications are summarized in Section 5 of this paper.

\subsection{Choosing to naturalize - Not a given}

Applying for citizenship, the process of naturalization, is not a requirement for obtaining legal permanent resident status. Rather, it is a voluntary decision that immigrants themselves make, upon becoming eligible for citizenship after residing in a country for a specified period of time. To some, it may seem like the natural last step of the initial immigration decision. The population in the receiving country, on the other hand, may be more accepting of those who naturalize and view them as fuller participants of society, since at the very least, new citizens can vote. Naturalization may also facilitate a more successful economic integration of immigrants, to the extent that potential employers see citizenship as a signal of positive characteristics and discriminate against those who are not citizens (Sumption and Flamm 2012). While earlier research has not found a significant income premium associated with naturalization (Chiswick 1978), more recent estimates suggest that citizenship does bring annual income gains from 5 to 20 percent, depending on the particular group of immigrants studied (Bratsberg, Ragan and Nasir 2002, Fix, Passel and Sucher 2003, DeVoretz and Belevander 2014, Pastor and Scoggins 2012).

In the United States, a foreign national applying for citizenship "must be at least 18 years of age; be a U.S. lawful permanent resident (LPR); and have resided in the country continuously for at least five years. Additional requirements include the ability to speak, read, and write the English language; knowledge of the U.S. government and history; and good moral character." 1 The applicant must also be willing to take the Oath of Allegiance and pay an application fee, regardless of whether the application is successful. Currently this fee is a relatively hefty $\$ 680$, having been raised a number of times in the past several years. The application fee was only $\$ 95$ in 1997 and in 2007, prior to the latest $85 \%$ increase, was $\$ 320.2$

With citizenship, the immigrant receives all the rights, benefits and responsibilities that the U.S. Constitution gives to all U.S. native-born citizens. If seeking it is a choice, a cost-benefit framework helps one understand how this decision is made. On the cost side are the financial outlay associated with the application fee, the requirement to give up one's original citizenship if dual citizenship is not possible, and the need to learn English if it is not known. The benefits include the right to sponsor relatives, access to federal government jobs, the right to vote, as well as the right to travel on a U.S. passport, with the increased protection (depending on the country the immigrant has left) that it may provide.

\section{$2.1 \quad$ U.S. Naturalization Rates are Low}

Lawful permanent residents in the United States naturalize at relatively low rates. This applies from both a historical and global perspective. In 1970, about two-thirds of all immigrants in the United States were naturalized, today this rate has fallen to under 50 percent. $^{3}$ This is also a low rate when compared to other immigrant receiving countries. For example, the Canadian naturalization rate, which in 1970 was at the same two-thirds level as the U.S. rate, has increased to well over 80 percent. The comparable rate in the United Kingdom is almost 70 percent and for Australia 85 percent (OECD 2011). ${ }^{4}$

The tendency to low naturalization rates in the United States also applies to undocumented individuals receiving legal status. A study by the U.S. Department of Homeland Security (Baker 2010), found that almost twenty-five years after the 1986 Immigration Reform and Control Act (IRCA), only 40 percent of the almost three million

\footnotetext{
1 Lee (2013). p.1

2 The current total fee consists of a $\$ 595$ application fee and an $\$ 85$ biometric fee that is used for background check costs. See website of US Citizenship and Immigration Services (USCIS) at http://www.uscitizenship.info/ins-citizenship-process.html. Unlike most other federal government agencies, USCIS ( which is a part of the Department of Homeland Security) operates primarily on the basis of the fees that it charges.

3 For example, as measured by the U.S. Census, 44 percent of all U.S. foreign born were citizens in 2010 . See www.census.gov/prod/2012pubs/acs-19.pdf.

${ }^{4}$ In the OECD study cited, the proportion of foreign born with citizenship for the United Kingdom was 67 percent, for Australia 81 percent, and for Canada 89 percent (OECD 2011).
} 
undocumented who had received amnesty and permanent residency under this major U.S. immigration legislation, had naturalized.

Since at least 2000, Mexico has been the top country of birth for people naturalizing in the United States, accounting for almost 15 percent of all naturalizations (Auclair and Batalova 2013). However, since Mexico is also by far the top country of birth of the U.S. foreign-born population, the proportion of Mexican immigrants naturalizing is notably low. Gonzales-Barrera et.al. (2013) have found this rate in 2011 to be only 36 percent, compared to 61 percent for immigrants from other Latin American and Caribbean countries, and 68 percent for all non-Mexican immigrants. ${ }^{5}$ Furthermore, a low Mexican naturalization rate has been a consistent feature over time, with evidence of a 35 percent Mexican naturalization rate in 2005 compared to 59 percent for other immigrants (Taylor 2006), and a 23 percent Mexican naturalization rate in 1990 compared to 40 percent for other immigrants (Bouvier 1996).

While the above discussion has focused on naturalization rates at the national level, we observe that there is a substantial regional variation as well. Using data from the American Community Survey (ACS) of the U.S. Census Bureau, we have calculated the share of citizens among immigrants (which we will henceforth refer to as the 'naturalization rate') for each state and the District of Columbia in 2013. Our estimates are derived by measuring the number of immigrants naturalized in 2013 as a proportion of the total foreign born population in each state and are presented in Table 1.6 This snapshot approach is the same approach that the U.S. Census Bureau has taken when calculating a national level of $44 \%{ }^{7}$ In other words, it is the percent of the state foreign born population in 2013 who were citizens and is the focus of our paper.

\begin{tabular}{lrlr}
\hline \multicolumn{4}{c}{ Table 1: Naturalization rates by state } \\
\hline State & NAT & State & NAT \\
\hline Vermont & 59 & Wisconsin & 44 \\
Hawaii & 57 & Louisiana & 42 \\
Montana & 57 & DC & 41 \\
Maine & 57 & Oregon & 40 \\
Alaska & 56 & South Carolina & 39 \\
New York & 54 & Georgia & 39 \\
New Hampshire & 54 & Colorado & 39 \\
New Jersey & 53 & Wyoming & 39 \\
Florida & 53 & Mississippi & 38 \\
Massachusetts & 52 & Tennessee & 38 \\
Minnesota & 52 & Idaho & 38 \\
Pennsylvania & 52 & Arizona & 38 \\
Rhode Island & 51 & Kentucky & 38 \\
& & & 37 \\
Michigan & 51 & Alabama & 56 \\
West Virginia & 51 & Iowa & 37 \\
Ohio & 50 & Utah & 37 \\
Maryland & 50 & Oklahoma & 35 \\
Virginia & 50 & Indiana & 35 \\
Connecticut & 49 & Texas & 34 \\
California & 49 & Nebraska & 34 \\
Illinois & 47 & New Mexico & 34 \\
Nevada & 47 & Kansas & 34 \\
Washington & 46 & Arkansas & 33 \\
Missouri & 45 & South Dakota & 33 \\
Delaware & 45 & North Carolina & 32 \\
& & North Dakota & 31 \\
\hline
\end{tabular}

Before proceeding to discuss the calculations presented in Table 1, it should be noted that there is no single or consistent way to estimate naturalization rates, and the method used can vary and is highly dependent on the

\footnotetext{
5 The number of years in LPR status prior to application is also longer for Mexicans, together with Canadians averaging ten years, compared to five years for Africans, six years for Asians and South Americans, seven years for Europeans and eight years for those from Oceania (Lee 2013).

${ }^{6}$ The data for the number of immigrants that have naturalized as well as for the number of foreign born by state is taken from U.S. Census Bureau, American Community Survey, Place of Birth by Nativity, 2013, Table B05002. State naturalization rates are rounded to the nearest percentage in Table 1. Our model has incorporated more precise numbers, to five decimal places, and these precise values are available upon request.

${ }^{7}$ See endnote 3 above.
} 
data available. For example, Fix, Passel and Sucher (2003) have estimated that in 2002 the U.S. naturalization rate for legal immigrants was 49 percent. Using this same methodology, Passel (2007) updated the naturalization rate for 2005 to 52 percent, but since not all legal immigrants are eligible to naturalize, subsequently recalculated this rate to be 59 percent. This underlines that the estimated rate is dependent on how the pool of immigrants is measured.

As a concept, the naturalization rate is clear: it is the proportion of eligible immigrants who have chosen to become citizens. While one knows the numerator - the actual number of people naturalizing or naturalized in any particular year - it is what is included in the denominator that makes estimates vary. The simplest approach, the one adopted in this paper, as well as by the U.S. Census Bureau and others, is to measure naturalized population as a proportion of the total foreign population in that same year (Camarota 2011). But this does not take into account the waiting period, and is therefore more than those 'eligible' since no time lag is included.

Furthermore, an immigrant becomes eligible upon meeting the required five years in residence, but may also remain eligible for ten, twenty, and more years if the choice not to apply is made. Some authors have used the stock of foreign born a number of years earlier as a proxy for those eligible. In a cross-country comparison, Picot and Hou (2011a) have estimated citizenship rates for foreign-born aged 25 and over in 2006 to be 47 percent for the United States and 79 percent for Canada in 2006, and then calculated this for only those who had been in the host country for 6 to 10 years, finding a naturalization rate of 24 percent for the United States and 71 percent for Canada. Sumption and Flamm (2012) have examined only foreign born who have arrived at least ten years prior.

A second overrepresentation of the denominator, especially in the United States, may occur if all foreign born are included, and not just authorized foreign born. In fact, a part of the decline in U.S. naturalization rates over time, and the lower U.S. rates in global comparisons, can be attributed to an increasing number of undocumented, who by definition cannot naturalize (Picot and Hou 2011b).

Therefore, one should be wary of comparing various authors' specific estimates of naturalization rates, due to differences in denominator choice. What matters is the consistency in calculation within a single study, in the case of our paper - citizenship share across states.

Initially, we set out to estimate state naturalization rates in 2013 using the following approach: calculating the number naturalized in each state in 2013 as a share of the average annual total foreign-born population in that state in 2006-2008 (in an attempt to account for the five year waiting period), and then netting from this total foreign born figure the number of undocumented in each state. ${ }^{8}$ We felt that this method would give us the best estimate of 'eligible' immigrants naturalizing.

Unfortunately, a further examination revealed that using the foreign born averages in 2006-2008 was not a valid proxy for the number of people in that state who would have been eligible to naturalize five years later - in 2013, due to significant variations over time in the state foreign born populations. For example, between 2008 and 2013 the total foreign born populations in Iowa and Kentucky increased by 30 percent, whereas in Maine this increase was only 4 percent and in Arizona there was a decrease of 5 percent. So as to have consistency in what we were measuring, we therefore had no choice but to use the total foreign born in 2013, thus asking the specific question - why are there proportionately more citizens in some states than others?

We also found that subtracting the number of undocumented from the total foreign born did not yield satisfactory naturalization rates at the state level, due to the wide range in the estimates available, relative to the size of state total foreign born. Such estimate ranges do not impact analysis at the national level, but because state level populations for our 51 observations in many cases are small, we were not able to generate reliable naturalization rates. For example, consider that it has been estimated that in 2010 there were approximately 11.2 million undocumented in the U.S. population, this estimate including a lower bound at 10.7 million and an upper bound at 11.7 million (Passel and Cohn 2011). For this same year, the approximate estimate of undocumented population in Alabama was 120,000, with a lower bound at 75,000 and an upper bound at $160,000 .{ }^{9}$ The national range of one million on a total foreign born base of 40 million is an error range of 3 percent, but on a foreign born base of 165,000 in Alabama the 85,000 estimated range is 50 percent. For some states this range was large, for others it was more like the national case. Therefore, calculating state naturalization rates using an adjustment for undocumented in the population based on average estimates of the undocumented did not allow us to generate consistent naturalization rates.

\footnotetext{
${ }^{8}$ Latest estimates of the undocumented population show rates have been relatively stable for the past three years ( Passel 2015 ).

${ }^{9}$ See Appendix A, Table 3 in Passel and Cohn (2011) for specific ranges in estimates of undocumented population for each state.
} 
Having explored an ideal way to calculate state naturalization rates, we found that the most consistent approach was indeed the one most commonly used - employing the stock of total foreign born in the denominator (OECD 2011). ${ }^{10}$ Thus, we measure the percent of total immigrants in 2013 who were citizens, where 44 percent is the national number. Table 1 shows that rates across states range from about one third naturalizing (31 percent in North Dakota, 32 percent in North Carolina) to as high as almost sixty percent naturalizing (57 percent in Montana and Maine, 59 percent in Vermont.)

In summary, based on our calculations in Table 1, the question that is the focus of this paper is: why does such a significant variation in immigrant naturalization rates exist across U.S. states? A brief review of the literature on the determinants of naturalization provides insight.

\subsection{The determinants of naturalization}

Research has attempted to measure the determinants of naturalization for the United States as well as other countries. Typically the approach has been to look at personal characteristics (age, gender, marital status), socio-economic characteristics (occupation, years of schooling, knowledge of the receiving country's language), as well as structural and institutional factors (recognition of dual citizenship, policies such as welfare reform changing the rate of return to citizenship) as the explanatory variables (Picot and Hou 2011b). For example, in general, women naturalize at a higher rate, as do those who are married or have lived in the country a longer time. Per capita income in the sending country also matters in that immigrants from developing countries have a higher citizenship rate. Higher skill and educational levels are also especially significant, as is knowledge of a country's official language. 11

Bloemraad (2006), in comparing Canadian and U.S. naturalization rates, has argued that these customary personal, demographic and socioeconomic determinants do not fully explain the differing rates. Rather, it is in institutional and policy variables, leading to a more welcoming Canadian environment to immigrants, where the answer lies. This has been reflected in something as simple as a shorter required residency (three years in Canada as opposed to five years in the United States) or something as all-encompassing as Canada's commitment to multiculturalism. "Multiculturalism ensures that all Canadians can keep their identities, can take pride in their ancestry and have a sense of belonging" (Citizenship and Immigration Canada 2014).

Emphasis on institutional variables is included in research examining migration in general. For example, Ashby (2010), while not looking at citizenship rates per se, analyzes motives for migration into OECD countries between 2001 and 2006 within a utility maximization framework. Using data for 58 countries, he considers the impact of changes in relative income as well as relative economic and political freedom on the probability of migration. He finds that economic and political freedom are significant determinants, because these freedoms are associated with greater economic opportunities (higher incomes allow one to enjoy more goods and services), and greater choice (greater political freedom allows one to use income how one sees fit), thus enhancing personal satisfaction. ${ }^{12}$ This is consistent with findings that Ashby (2007) has made for U.S. internal migration, concluding that, "relative economic freedom had a positive, indirect impact on state-to-state migration flows between 1995-2000 in the lower 48 states." 13 Using both panel and cross sectional data, he finds that economic freedom is positive and statistically significant in predicting migration, while political freedom is negative and significant in all regressions.

Peridy (2006), in examining immigration to the EU, has shown that policy regulations that reflect a more open and welcoming approach to immigration ( such as number of residence permits given out by the destination country) and public spending on immigrants can create the effect of a welfare magnet, becoming important immigrant pull variables. Leon and Aleman (2014) find that psychological factors (especially those leading to negative emotions) and social institutional factors (such as the opportunity for social integration) are primary determinants of immigrants to the Canary Islands in their decision to stay or return.

\footnotetext{
10 Our denominator includes authorized immigrants who have both naturalized and not naturalized in 2013, as well as undocumented foreign born. These foreign born stock values correlate at .9 with estimates - available for 20 states - that the DHS has made of lawful permanent residents in 2013 eligible to naturalize but who have not yet naturalized (Baker and Rytina 2015).

11 Using a large data set containing detailed individual characteristics, Yang (1994) was one of the first to quantitatively establish that knowledge of a country's official language is a key predictor of whether an immigrant will naturalize. See Picot and Hou (2011a) for an excellent survey of the literature on the determinants of naturalization.

12 Ashby defines economic freedom as the freedom to benefit from the fruit of one's labor through voluntary exchange while allowing the same rights to others. Political freedom is the absence of coercion by others and by the government, e.g. freedom of religion, assembly, press, personal autonomy.

13 Ashby (2007), p. 49.
} 


\subsection{The model}

From the literature, we see that immigrants are responsive not only to economic variables, but also to social and political variables that provide a welcoming environment. Our model will therefore include not only economic factors but the extent to which there is a socio-politically welcoming environment. In fact, in the decision to naturalize, which after all is a decision about joining a given society, a welcoming environment may be especially important. In addition, given that naturalization rates vary by country of origin, we will include consideration of the composition of immigrants in a particular region. Finally, we understand that naturalization rates - when measured as a percent of total foreign born - may be low due to the fact that the share of the undocumented (ineligible) population in a particular state is high, and so we will explore this factor as well.

To evaluate observed state level variation in naturalization rates among U.S. immigrants in 2013, we focus on four primary determinants; economic conditions in the state, the socio-politically welcoming environment of the state, the percent of Mexicans among the foreign born in the state, as well as state level estimates of the number of undocumented immigrants. Specifically, we have state level data and are modeling:

$$
N A T_{i}=b_{0}+b_{1}\left(E C_{i}\right)+b_{2}\left(S W E_{i}\right)+b_{3}\left(M X_{i}\right)+b_{4}\left(U N D O C_{i}\right)+\varepsilon_{i}
$$

where the dependent variable $\mathrm{NAT}_{i}$ measures the immigrant naturalization rate in a particular state, as calculated and presented in Table 1.

Economic conditions in each state are reflected in variable $\mathrm{EC}_{i}$, and computed as the sum of normalized values for the median income of the state, the percent of the state population living above the poverty line, and a measure of equality using the Gini coefficient. ${ }^{14} \mathrm{~A}$ composite variable is used here to control for state level variation in economic conditions without constraining sample size. As our focus is on the impact of geographic region on naturalization rates, we do not parcel out the independent impacts of each component of the $\mathrm{EC}_{\mathrm{i}}$ variable, but instead focus on generating an economically sound model. Higher values of EC indicate better economic conditions within the state; higher median income, less people in poverty and greater equality. It is anticipated that the parameter estimate $\mathrm{b}_{1}$ will be greater than zero, indicating that states with better economic conditions will have higher naturalization rates.

The variable $\mathrm{SWE}_{i}$ measures the 'socio-politically welcoming' environment of a state (also referred to as 'socially welcoming' environment in the remainder of the paper) and is created as the sum of normalized values of the percent of eligible voters that voted in the 2010 elections, the Democrat/Republican gap in voter registration in 2008, education spending as a portion of state GDP in 2010, and the inverse of normalized values of three variables measuring state level attitudes toward undocumented immigrants. ${ }^{15}$ Higher values for $\mathrm{SWE}_{i}$ indicate a more liberal and engaged social and political state landscape. ${ }^{16}$ We use a composite variable here as well to control for variation in the social environment of a state without constraining sample size. While results regarding the impact of changes in the 'socio-politically welcoming' environment of a state will be reported, we cannot parcel out the independent impact of each component. It is anticipated that the parameter $\mathrm{b}_{2}$ will be positive, indicating that states that are more socially and politically welcoming to immigrants will have higher rates of naturalization than states with less welcoming environments. The variable $\mathrm{MX}_{i}$ measures the share of the state total foreign born population that is from Mexico. ${ }^{17}$ As noted earlier, research shows that Mexican immigrants naturalize at a lower rate than other immigrant groups in the United States, so we anticipate that the sign on $b_{3}$ will be negative.

\footnotetext{
${ }^{14}$ The measure of equality is equal to one minus the Gini coefficient of each state. Data for the Gini coefficient is available from the U.S. Census Bureau, American Community Survey, Index of Income Inequality, 2010, Table B19083 and data for the percent of the state population living below the poverty line is from the U.S. Census Bureau, Statistical Abstract of the United States, Persons Below Poverty Line, 2008. Data for state median income is from the U.S. Census Bureau, American Community Survey, Median Household Income by State - Single Year Estimates, 2010, Table H-8.

15 The state turnout rates are computed by Michael McDonald and are taken from www.electproject.org/2010g and represent the 2010 November General Election Turnout Rates for the voting eligible population. Data for the Democrat- Republican Gap is from Jones, Jeffrey M., "State of the States: Political Party Affiliation". Gallup. January 28, 2009 (available at http://www.gallup.com/poll/114016/state-statespolitical-party-affiliation.aspx). Education spending as a percent of state GDP is available from the U.S. Census Bureau, Annual Survey of Government Finances, Current Spending of Public Elementary School Systems by State 2009-2010, Table 6. (available at www.census.gov/govs/school/historical_data_2010.html). We use three state level variables as reported by Park (2015) to measure attitudes toward immigrants; whether state law allows access to public colleges at an in-state rate for undocumented immigrants, whether local law enforcement is legally allowed to ask individuals about immigrant status, and whether the state has filed a lawsuit challenging the Obama Executive action allowing work permits and deportation protection to unauthorized immigrants.

16 This variable is constructed from available state level data to measure and evaluate the characteristics consumers use to make residential decisions. The top items cited in the mainstream literature include jobs, crime and climate as well as taxes, culture, family and friends, community and politics, faith based preferences, and education, and it is these latter six items that we are in part capturing with the socially welcoming variable.

${ }^{17}$ Data was available at Migration Information Source ( Migration Policy Institute) and was computed using data from the US Census Bureau $1990-2010$.
} 
The final variable, UNDOC $_{\mathrm{i}}$ is an estimate of the number of unauthorized immigrants in each state in 2012.18 It is expected that the sign of the coefficient $b_{4}$ will be negative. However, because our model separates out and accounts for the percent of Mexicans among the foreign born, it changes the interpretation of the parameter estimate $b_{4}$ and may alter the sign or significance of the number of unauthorized immigrants in determining the state naturalization rate. While at the national level, almost 60 percent of the undocumented are from Mexico (Passel 2015), we find variations across states, and a statistically insignificant correlation between MX and UNDOC of only 0.2169 . We therefore consider both as independent explanatory variables in our equation.

Descriptive statistics appear below in Table 2. As has been noted earlier in the paper, while the national naturalization rate has been estimated at 44 percent ( 0.440 mean in Table 2$)$, there is a wide variation across individual states (Table 1). Economic conditions also vary considerably across the United States. We find that they are best in New Hampshire (value of 5.35) and worst in the District of Columbia (value of -5.08). There is also considerable variation in the share of foreign born in a state that are of Mexican origin - with values ranging from a low of one percent (in Maine) to a high of 73 percent (in New Mexico) and a mean across the United States of 25.71 percent. Measures of a state's socially welcoming environment vary from the most engaged or welcoming in Vermont (6.44) to least welcoming in Arizona (-8.52).

\begin{tabular}{lrrrrr}
\hline \multicolumn{5}{c}{ Table 2: Descriptive statistics } & \\
\hline NAT & $\mathrm{n}$ & mean & std. dev. & min & max \\
EC & 51 & 0.440 & 0.0817 & 0.3102 & 0.589 \\
SWE & 51 & 0.00000116 & 2.438 & -5.079 & 5.348 \\
MX & 51 & 0.000000119 & 3.276 & -8.518 & 6.441 \\
UNDOC & 51 & 25.705 & 19.412 & 1.00 & 73.00 \\
\hline
\end{tabular}

Pair wise correlations indicate that each of the independent variables has a statistically significant relationship with the ratio of immigrants naturalized in any state and the correlations for EC, SWE and MX have the expected signs and are hence, consistent with our hypotheses. Table 3 shows that improvements in the economic conditions of the state are correlated with a higher percent of immigrants naturalized in that state, and that a more socially welcoming state landscape is correlated with a higher naturalization rate. Table 3 also shows that states with a higher Mexican share of foreign born have a statistically significant lower percent of immigrants that are naturalized. The correlation between UNDOC and NAT, although not statistically different from zero, has a sign different from what we were expecting, suggesting that where there are more undocumented amongst the foreign born, there are more immigrants naturalizing.

\begin{tabular}{lccrrr}
\hline \multicolumn{5}{c}{ Table 3: Correlations } \\
\hline NAT & NAT & EC & SWE & MX & UNDOC \\
EC & 1.00 & & & & \\
SWE & $0.3702^{*}$ & 1.00 & & & \\
MX & $0.5117^{*}$ & $0.3361^{*}$ & 1.00 & & \\
UNDOC & $-0.7153^{*}$ & -0.2406 & $-0.4144^{*}$ & 1.00 & \\
\hline *statistically significant $(\alpha=0.05)$. & 0.0614 & -0.1294 & -0.0686 & 0.2169 & 1.00 \\
\hline
\end{tabular}

\subsection{The empirical results}

With fifty one observations (50 states and the District of Columbia) and a well specified model, we find that 64.2 percent of the state level variation in naturalization rates among immigrants is explained, as seen in Table $4 .{ }^{19}$ The statistically significant $(\alpha=0.05)$ parameter estimate on economic conditions (EC), indicates that states with lower inequality, higher mean incomes, and a smaller percent of the population living below the poverty line have a greater percent of immigrants that seek citizenship. For example, differences in economic conditions between Mississippi and New Hampshire represent a change in the value of EC from -5.079 to 5.348 and this change translates into a $14.2 \%$ change in naturalization rates according to our model. Citizenship, and thus the fuller integration of immigrants, is more likely in areas where there are more welcoming economic environments.

\footnotetext{
18 Passel (2015).

19 To evaluate the possibility of a nonconstant variance in the error term, we ran the Breusch-Pagan test for heteroscedasticity and with Chisquare statistic of 0.79 (probchi $2=0.3741$ ) we fail to reject the null hypothesis $\left(\mathrm{H}_{0}:\left(\mathrm{U}_{\mathrm{i}} \mid \mathrm{X}_{\mathrm{i}}\right)=\sigma^{2}\right)$ that errors are homoskedastic. This result is consistent with visual inspection of the residual scatterplot (available from authors upon request).
} 
In addition, the positive parameter estimate on the variable measuring socially welcoming conditions (SWE) indicates that states with a higher voter turnout, a larger Democrat to Republican ratio, higher spending on education, and greater social rights and opportunities extended to undocumented immigrants will have a statistically significant $(\alpha=0.05)$ and greater share of immigrants naturalizing. In this instance, the independent impact on naturalization rates from a change in the SWE variable from the low of -8.51 found in Arizona to the highest value of 6.44 in Vermont is $17.3 \%$.

Although we see solid evidence that states with more economically vibrant economies and more socially liberal indicators will see a greater naturalization of immigrants, it is also noted that the socially welcoming environment seems to be a somewhat stronger indicator. Our findings support the proposition that while immigrants may move for economic opportunities, they stay where there is a comfortable and socially welcoming environment. Our findings are consistent with those of Ashby (2010) that economic and political freedoms impact immigrants, as well as those of Bloemraad (2006) and Leon and Aleman (2012) who argue that a more welcoming socio-political environment will lead to greater immigrant participation.

\begin{tabular}{lrrr}
\hline \multicolumn{4}{c}{ Table 4: Impact on naturalization rates } \\
\hline variable & coefficient & Standard error & t-stat \\
\hline EC & 0.0060 & 0.00325 & 1.89 \\
SWE & 0.0051 & 0.00255 & 2.01 \\
MX & -0.0027 & 0.000421 & -6.43 \\
UNDOC & 0.0000005 & 0.00000002 & 2.61 \\
Cons. & 0.4992 & 0.0129 & 38.82 \\
\hline Dependent variable is the percent of immigrants that seek citizenship, by state (NAT). \\
The model has an $\mathrm{R}^{2}=0.642$ and adjusted $\mathrm{R}^{2}=0.611$.
\end{tabular}

The data also suggest a significant network or clustering effect on naturalization rates, as measured by the country of origin, thus composition, of immigrants. In particular, where there is a greater share of Mexican immigrants among the state foreign-born, there is a lower percent of immigrants seeking citizenship in those states. For example, the data suggest that the difference in the percentage of Mexicans naturalizing between Maine and New Mexico (where we see the lowest and highest percent of immigrants from Mexico, respectively), results in a $44 \%$ decrease in naturalization rates. This finding is consistent with that of Gonzales-Barrera et al. (2013) and other research that has underlined that naturalization rates have been, and continue to be, lowest among immigrants from Mexico.

Finally, the statistically significant parameter estimate on UNDOC indicates that states with higher numbers of unauthorized immigrants have a slightly higher (albeit very small) rate of naturalization. Although at first appearing counter intuitive, it may be that this is reflective of a psychological effect on some authorized immigrants, who wish to underline that they are not undocumented and do so by becoming citizens. Such an effect would be expected to be greater in states with proportionately larger shares of undocumented immigrants. This is consistent with research that has shown that legal immigrants do sometimes separate themselves from the undocumented, as was the case in the voting results of California's Proposition 187, which saw a split among legal immigrants based on whether they had become citizens. In particular, Latinos who were non-citizens overwhelmingly opposed the proposition, and Latinos who were citizens supported this antiundocumented immigrant proposition (Newton 1998). ${ }^{20}$ Results such as these, showing that not all authorized immigrants view the undocumented in the same way, may also be a reason for our very small coefficient, since the actions of one group of authorized immigrants may be offsetting those of the other. Our findings certainly indicate that further investigation into how legal immigrants behave, when the share of the undocumented population increases, warrants further study.

\subsection{Conclusion and policy implications}

This paper has shed light on why some U.S. states have a greater share of naturalized citizens among their foreign born than others. While the proportion of all foreign born who are citizens is $44 \%$ at the national level, across states, we see a range from a low of about $30 \%$ to a high of almost $60 \%$. Although we recognize that applying for citizenship is an individual decision, we have attempted to examine how much institutional and group variables may influence this decision. In particular, as expected, we have found that a more favorable economic environment is correlated with higher naturalization rates.

\footnotetext{
${ }^{20}$ More recently, Congressman John Salazar of Colorado, during an attempt to pass comprehensive immigration reform, was "berated by Mexican-American constituents whose families had been in his valley 'forever'. They asked him why he was trying to help the mojados (wetbacks) - a pejorative for Mexicans supposed to have swum across the Rio Grande" from the Economist Magazine, Special Report: America's Hispanics, March 14, 2015.
} 
We have also found that an environment that is more socially and politically welcoming to immigrants has a positive and statistically significant impact on naturalization rates. Our research supports the proposition that attitudes towards immigrants, be they authorized or undocumented, does influence the extent to which the foreign born become fuller participants in U.S. society. To the extent that citizenship is a proxy for successful integration, policy makers, wishing to increase naturalization rates, should focus on variables that make immigrants feel more welcome. This is especially important today, as the pendulum swings increasingly towards anti-immigrant attitudes, be it in the United States or in the EU.

Another of our findings is that the share of foreign born that are undocumented in a state weakly correlates with naturalization rates, but not in a manner that we had expected. In particular, as the proportion of undocumented increases, the share of foreign born who are citizens does not decrease, but increases. Our suspicion is that when the undocumented population is large, some legal immigrants may choose to differentiate themselves from the undocumented by becoming citizens. In other words, some immigrants who are legally in the United States may choose not to identify with the undocumented foreign born, even if they are from the same country. Our paper suggests further research into how unified the voice of authorized immigrants is, especially on the subject of undocumented immigration.

The inclination of immigrants to cluster geographically, thus the composition of the foreign born on the basis of country of origin, is another factor that explains differences in state naturalization rates. Specifically, we have observed that where there are more Mexicans among the foreign born, the share of naturalized citizens is lower. The reasons for this appear to be more than the fact that the undocumented (those who cannot naturalize) are disproportionately from Mexico. A recent examination of why Mexican immigrants don't naturalize has been undertaken by the Pew Research Center (Gonzales-Barrera, et al. 2013). Explanatory factors include: not knowing that giving up Mexican citizenship is no longer a requirement for U.S. naturalization, and that the high application fee is discouraging the naturalization of immigrants. Other obstacles, however, are more overwhelming and will take time to surmount. These barriers keep Mexican immigrants from passing the citizenship test either directly, such as lack of English proficiency and low levels of education, or indirectly, such as low earnings and long working hours, which do not allow for preparation for the test.

The Pew Center research reveals that two relatively simple and inexpensive policy steps (getting the message out to Mexicans living legally in the United States that the possibility of dual citizenship exists, and lowering the application fee for U.S. naturalization) could readily increase the number of Mexicans applying for U.S. citizenship. Building on this, our work shows that policy steps that increase Mexican naturalization rates, will substantially increase overall U.S. citizenship rates. Depending on which party is in power, however, implementing such policy may or may not be desirable. For example, to the extent that there is a 'Mexican immigrant' vote, this will definitely be magnified if naturalization rates of Mexican immigrants increase.

At present, increasing the share of naturalized citizens is not an explicit goal of U.S. immigration policy. Political rhetoric on immigration focuses on border security, reducing undocumented entries, increasing skilled legal entries and other issues. Most of the electorate does not even realize that legal immigrants do not all become citizens, and that applying for citizenship is not a requirement for legal status. The blurring of terms adds to the disconnect between reality and perception. Be it political rhetoric or media coverage, the words 'immigrant', 'citizen', and 'undocumented' are too often used interchangeably, which only furthers the confusion. This paper has been an attempt to add some clarity to the issue of immigrant naturalization, and to evaluate institutional factors that affect the propensity of U.S. immigrants to become citizens.

\section{References}

Ashby, N., (2007). Economic freedom and migration flows between U.S. states. Southern Economic Journal 73 (3): 667-697

Ashby, N., (2010). Freedom and international migration. Southern Economic Journal 77 (1): 49 - 62. July. http://dx.doi.org/10.4284/sej.2010.77.1.49

Auclair, G., and Jeanne B., (2013). Naturalization trends in the United States. Migration Policy Institute, Washington, D.C.

Baker, B., (2010.) Naturalization rates among IRCA immigrants: a 2009 update. Office of Immigration Statistics. United States Department of Homeland Security.

Baker, B. and Nancy R., (2014). Estimates of the lawful permanent resident population in the United States: January 2013. Office of Immigration Statistics. United States Department of Homeland Security.

Bloemraad, I., (2006). Becoming a Citizen: Incorporating Immigrants and Refugees in the United States and Canada. Berkeley, CA: University of California Press. 
Bouvier, L. F, (1996). Embracing America. Center for Immigration Studies. Washington, D.C.

Bratsberg, B., Ragan, J., and Nasir, Z., (2002). The effect of naturalisation on wage growth: a panel study of young male immigrants. Journal of Labor Economics 20 (3): 568-597. http://dx.doi.org/10.1086/339616

Camarota, S., (2011). A record-setting decade of immigration: 2000-2010. Center for Immigration Studies. Washington, D.C.

Chiswick, B., (1978). The effect of americanization on the earnings of foreign-born Mexicans. Journal of Political Economy 69:897-921. http://dx.doi.org/10.1086/260717

Citizenship and Immigration Canada, (2014). Canadian Multiculturalism: An Inclusive Citizenship. Available at http://www.cic.gc.ca/english/multiculturalism/citizenship.asp.

DeVoretz, D., and Bevelander, P., (2014). The economic case for a clear, quick pathway to citizenship: evidence from Europe and North America. Center for American Progress.

Fix, M., Passel, J., and Sucher, K., (2003). Immigrant families and workers: trends in naturalization. Urban Institute Immigration Studies Program.

Griffith, A., (2013). Policy Arrogance or Innocent Bias: Resetting Citizenship and Multiculturalism. Anar Press.

Gonzales-Barrera, A., Hugo Lopez, M., Passel, J.S., and Taylor, P., (2013). The path not taken: two-thirds of legal Mexican immigrants are not U.S. citizens. Pew Research Center.

Lee, J., (2013). U.S. Naturalizations: 2012. United States Department of Homeland Security.

Leon, C., and Aleman, A.H., (2014). Immigrants' decision to stay in the Canary Islands: a latent class approach. Regional Studies 48 (10): 396-403.

Newton, L., (1998). Why Latinos supported Proposition 187: testing the economic threat and cultural identity hypotheses. Center for the Study of Democracy. UC Irvine Research Papers.

OECD, (2011). Naturalization: A Passport for the Better Integration of Immigrants? OECD Press.

Park, H., (2015). Which states make life easier or harder for illegal immigrants? New York Times. March 29

Passel, J., (2007). Growing share of immigrants choosing naturalization. Pew Research Center. March.

Passel, J., and D'Vera C., (2011). Unauthorized immigrant population: national and state trends, 2010. Pew Research Center. February.

Passel, J., (2015). Unauthorized immigrant population: national and state trends, industries and occupations. Testimony to U.S. Senate Committee on Homeland Security and Governmental Affairs. March 26.

Pastor, M., and Scoggins, J., (2012). Citizen gain: the economic benefits of naturalization for immigrants and the economy. Center for the Study of Immigrant Integration, University of Southern California.

Pastor, M., and Sanchez, J., (2012). Rock the (naturalized) vote: the size and location of the recently naturalized voting age citizen population. Center for the Study of Immigrant Integration, University of Southern California. October.

Pastor, M., and Marcelli, E. A., (2013). What's at stake for the state: undocumented Californians, immigration reform and our future together. Center for the Study of Immigrant Integration, University of Southern California. May.

Peridy, N., (2006). Welfare magnets, border effects or policy regulations: what determinants drive migration flows into the EU? Global Economy Journal 6 (4):1 - 35. http://dx.doi.org/10.2202/1524-5861.1186

Picot, G., and Hou, F., (2011a). Citizenship acquisition in Canada and the United States: determinants and economic benefit. In Naturalisation: A Passport for the Better Integration of Immigrants? Paris. OECD Press.

Picot, G., and Hou, F., (2011b). Divergent Trends in Citizenship Rates among Immigrants in Canada and the United States. Ottawa: Statistics Canada.

Sumption, M., and Flamm, S., (2012). The economic value of citizenship for immigrants in the United States. Migration Policy Institute. September.

Taylor, D. G., (2006). The naturalization trail: Mexican naturalization and U.S. citizenship. Latino Research 3 (2): $1-8$.

United States Senate, (2013). Bill S.744 - The Border Security, Economic Opportunity, and Immigration Modernization Act. Washington, DC.

Yang, P. Q., (1994). Explaining immigrant naturalization. International Migration Review 28 (3): 449-77. http://dx.doi.org/10.2307/2546816 